\title{
Changes in the life history traits of the European Map butterfly, Araschnia levana (Lepidoptera: Nymphalidae) with increase in altitude
}

\author{
KATHRIN D. WAGNER ${ }^{1,2}$, Jochen KRAUSS ${ }^{1,2}$ and INGOLF STEFFAN-DEWENTER ${ }^{1,2}$ \\ ${ }^{1}$ Population Ecology Group, Department of Animal Ecology I, University of Bayreuth, Universitätsstrasse 30, 95447 Bayreuth, \\ Germany; e-mail: kathrin.wagner@uni-bayreuth.de \\ ${ }^{2}$ Department of Animal Ecology and Tropical Biology, University of Würzburg, Biocentre, Am Hubland, 97074 Würzburg, \\ Germany
}

Key words. Nymphalidae, Araschnia levana, global change, altitudinal gradients, trophic interactions, geographical synchronisation

\begin{abstract}
Climatic conditions can modify the life history traits, population dynamics and biotic interactions of species. Therefore, adaptations to environmental factors such as temperature are crucial for species survival at different altitudes. These adaptive responses, genetically fixed or plastic (phenotypic plasticity), can be determined by physiological thresholds and might vary between sexes. The objective of this study was to determine whether the life history traits of the European Map butterfly (Araschnia levana) differ at different altitudes. A field experiment was carried out along an altitudinal gradient from 350 to $1010 \mathrm{~m}$ a.s.l. in a low mountainous region (Bavaria, Germany). 540 butterfly larvae were placed at different altitudes in 18 planted plots of their larval host plant, the stinging nettle (Urtica dioica). After three weeks the larvae were collected and reared under laboratory conditions. Developmental traits of the butterflies, mortality and percentage parasitism were measured. Larval development was generally slower at higher altitudes and lower temperatures and larval weight decreased with increasing altitude and decreasing temperature. However, there were no significant differences in pupation, adult lifespan and percentage mortality at the different altitudes and temperatures. Female larvae were heavier than those of males, and the pupal and adult lifespans were longer in females than in males. However, male and female butterflies reacted similarly to altitude and temperature (no significant interactions). None of the 188 larvae collected were parasitized. In conclusion, the phenotypic plasticity of European Map butterfly has enabled it to adapt to different temperatures, but the strategies of the sexes did not differ.
\end{abstract}

\section{INTRODUCTION}

Environmental and climatic conditions determine the limits of the ranges of many plant and animal species (Warren et al., 2001; Franco et al., 2006; Parmesan, 2006). Increasing temperatures, caused by climate warming, can modify species life history traits and may result in reduced or enhanced species survival (Bale et al., 2002). If species specific tolerances to temperature are exceeded, the phenology of plants and animals or their distribution will change or they will go extinct (Parmesan \& Yohe, 2003; Root et al., 2003; Primack et al., 2009). Therefore, species might expand their ranges into cool regions, polewards or move to higher altitudes (Wilson et al., 2007; Merrill et al., 2008). Life history traits can facilitate or impede species migration and shifts in geographic distribution (Berner et al., 2004).

Insects, especially, should be affected by temperature, because of their short life cycles, ectothermic physiology and often low dispersal ability (Bourn \& Thomas, 2002). Increasing temperature can cause physiological changes in insects, like deviations in diapause or dormancy. In mountainous regions insects often have to adapt to fragmented habitats and harsh environmental conditions (Hodkinson, 2005). Therefore rapid changes in mountain communities can be expected as the climate changes (McCarty, 2001). However, there are only a few altitudinal studies on the effect of temperature on insects (e.g. Karl et al., 2008). Recent studies show that insects at higher altitudes adapt to lower temperatures by having fewer instars and generations per year (Hodkinson, 2005). Enhanced adaptation to local climate and altitude can be facilitated by high phenotypic plasticity (Karl et al., 2008). Alpine species of insects, for example, are often better adapted to low temperatures than widespread species (Buse et al., 2001). Body size can increase with increasing altitude (Angilletta \& Dunham, 2003; Karl \& Fischer, 2008) and species fitness can decrease at low temperatures (Hodkinson, 2005).

Extreme environmental conditions have different effects on different trophic levels (Schweiger et al., 2010). At high altitudes insects like parasitoids have to adapt to both host dynamics and to harsh environmental conditions, which might result in a decrease in the rates of parasitisation (Both et al., 2009; Holt \& Barfield, 2009). Slower development of host species in colder habitats also increases the time for which they are vulnerable and can result in an increased risk of predation and parasitism, according to the slow-growth-high-mortality hypothesis (Benrey \& Denno, 1997).

Most altitudinal studies on the effects of temperature are laboratory based (e.g. Karl et al., 2008). Field studies on the relation between altitude and life history parameters are still rare, but of particular importance since individuals live in the context of complex environmental and trophic interactions. The aim of this experimental field study is to disentangle potential effects of altitudinal gra- 
dients on the life history of Araschnia levana and its hostparasitoid interactions. The butterfly A. levana is a good model species as it extended its distribution over the last few decades (Parmesan et al., 1999; Parmesan, 2001; Konvicka et al., 2003) and therefore the butterfly and interacting species might not be optimally adapted and synchronized. A. levana occurs naturally along the whole altitudinal gradient in the study region and because it is bivoltine it is easily reared. Developmental time, mortality and percentage parasitism of larvae placed in experiment plots along an altitudinal gradient were measured. It was hypothesized that: (1) butterflies reared at high altitudes will take longer to develop, be lower in weight and fewer will survive because of the more unsuitable climatic conditions there, compared to low altitudes and that (2) fewer of the butterfly larvae transferred to high altitude sites will be parasitized than of those transferred to low altitude sites.

\section{MATERIAL AND METHODS}

\section{Study region and experimental sites}

The study region is located in the nature park Fichtelgebirge, a low-mountain region in northern Bavaria (Germany) close to the boarder with the Czech Republic east of the German town Bayreuth. The altitude ranges up to $1051 \mathrm{~m}$ a.s.l. Eighteen sites, covering the whole altitudinal gradient from about 350 up to $1010 \mathrm{~m}$, were selected. The sites were located in fields next to forest and shrubs, where A. levana populations occurred naturally. At each of the 18 sites patches of the main larval food plant of A. levana, nettle Urtica dioica, were established.

\section{Experimental design}

In October and November $20081 \mathrm{~m}^{2}$ sized patches of $U$. dioica were established at each of the 18 study sites by planting four pots of $U$. dioica. Study sites were located next to natural $U$. dioica patches. To assure that the larval food plants had the same phenological and genetic background commercially available seeds (Appels Wilde Samen, Darmstadt, Germany) were used. In contrast to vegetatively reproduced plants the seeds have the advantage that they are homogenous and allow fast and repeatable growing of one genetically homogenous cultivar. Seedlings were reared in a greenhouse and each planted in a 101 plant pot containing potting soil with osmocote fertiliser $(0.3 \%)$. After six months in the greenhouse the plants were transferred to the field. When necessary the plants at the study sites were protected from large herbivores by surrounding the patches with wire mesh fences. The nettles were initially watered. To obtain the average temperatures along the altitudinal gradient the temperature every second hour at each of the 18 nettle sites along the altitudinal gradient (06 June - 08 July 2009) was measured using iButtons dataloggers (Maxim Integrated Products Inc., Sunnyvale, CA, USA).

\section{Study species}

The European Map butterfly Araschnia levana (Linnaeus, 1758) (Lepidoptera: Nymphalidae) is a widespread species in Europe and has recently expanded its range in all directions and colonized higher altitudes (Parmesan et al., 1999; Parmesan, 2001; Konvicka et al., 2003). The species occurs naturally in the Fichtelgebirge and has two polymorphic generations per year (in the intensive surveys carried out in 2008, spring and summer generations were detected up to $800 \mathrm{~m}$; Wagner unpublished data). A partial third generation is possible in warmer regions in southern Germany and is recorded only for places below $400 \mathrm{~m}$ a.s.l. (Ebert \& Rennwald, 1991). The generations of A. levana in spring and summer differ in wing colour (Fric \& Konvicka, 2002). The larval host plant of A. levana is the stinging nettle, $U$. dioica, but it might also feed on other Urtica species (Ebert \& Rennwald, 1991). The butterfly lays eggs in long strings on the underside of nettle leaves, where the larvae develop in groups of between 10-30 individuals until the last larval stage. In the field pupae are rarely found on the larval host plant, perhaps because the larvae disperse from the host plant before pupating (Ebert \& Rennwald, 1991). Most of the parasitoids of butterflies attack the first or second instar larvae and emerge from the fifth instar or pupae (see for example Brückmann et al., 2011). Parasitoids recorded from A. levana, are the two ichneumonids Apechthis compunctor and Thyrateles camelinus, and the tachinids Bactromyia aurulenta, Compsilura concinnata, Phryxe nemea, Phryxe vulgaris and Sturmia bella (Hertin \& Simmonds, 1976). Other parasitoids e.g. braconids are also commonly recorded parasitizing butterflies (Hertin \& Simmonds, 1976).

In March 200915 first generation individuals of $A$. levana were caught at a location about three kilometres from the nearest study site $\left(300 \mathrm{~m}\right.$ a.s.1., $\left.49^{\circ} 54^{\prime} \mathrm{N}, 11^{\circ} 40^{\prime} \mathrm{E}\right)$. This location was chosen as the individuals there are probably similar genetically to the natural populations in the study region. To encourage the butterflies to reproduce they were kept in a climate chamber $\left(22^{\circ} \mathrm{C}, 16 \mathrm{~L}: 8 \mathrm{D}\right)$. As it was unknown whether the females had already mated in the field, both males and females were placed together in a cage $(50 \times 50 \times 70 \mathrm{~cm})$ with $U$. dioica, flowering plants, sucrose solution and water, which are the optimum conditions for reproduction. Females were allowed to deposit eggs on the nettles. To synchronize egg hatching, the eggs were collected and kept at $14^{\circ} \mathrm{C}(16 \mathrm{~L}: 8 \mathrm{D})$. Afterwards the eggs were kept at $22^{\circ} \mathrm{C}(16 \mathrm{~L}: 8 \mathrm{D})$ to induce hatching. The first and second instar larvae were randomly distributed between the experimental nettle patches at the study sites in the Fichtelgebirge (09-10 June 2009). 30 larvae were put on the nettles at each site. After three weeks (01-02 July 2009) the larvae were collected and were in the fourth to fifth instar, but had not yet pupated. Therefore, the larvae could have been attacked by parasitoids but they would not have emerged before collection (Brückmann et al., 2011). The larvae spent three weeks in the field and adapted to the climatic conditions at the study sites before they were collected and transferred in the laboratory. These larvae were placed individually in boxes $(125 \mathrm{ml})$ with moistened filter paper and leaves of $U$. dioica $\left(22^{\circ} \mathrm{C}, 16 \mathrm{~L}: 8 \mathrm{D}\right)$. When necessary the boxes were supplied with new leaves. The weights (in $\mathrm{mg}$ ) of the larvae (directly after collecting) and pupae (one day after pupation) and the larval development time from collection in the field to pupation in the laboratory (in days) and the time spent in the pupal stage, were recorded. The butterflies that emerged from the pupae were placed in boxes (1 1 ) and provided with sucrose solution and water. Adult life span was recorded (in days from emergence to natural death). Percentage mortality of the 30 larvae transferred to each site and percentage mortality which occurred after collecting the larvae and prior to adult emergence in the laboratory was calculated for each site. Sex was determined after the adults emerged from the pupae.

\section{Statistical analyses}

The statistical analyses were conducted in $\mathrm{R}$ (v. 2.10.1). Linear mixed effect models (library nlme; Pinheiro et al., 2010) with a maximum likelihood method were calculated with the fixed effects sex at first position and either temperature or altitude at the second position plus the interaction between $\operatorname{sex} x$ altitude or sex $\times$ temperature. As it was not possible to deter- 
mine the sex of all the individuals due to mortality during development, the analyses were carried out with and without sex as a fixed factor. However, the results were consistent and only the data with sex as a cofactor is presented. The following 7 response variables were recorded: (1) larval weight, (2) pupal weight, (3) larval development time from collecting to pupation, (4) duration of pupation, (5) adult lifespan (6) percentage larval mortality in the field and (7) percentage larval mortality in the laboratory. Percentage larval mortality for each site was arcsin- sqrt transformed. As the mortality rates are a single value at each site and the sex of the individuals that died was unknown, simple regressions with altitude and temperature were calculated.

\section{RESULTS}

Temperature decreased with increase in altitude $(\mathrm{y}=$ $-0.0059 \mathrm{x}+20.13 ; \mathrm{R}^{2}=0.885 ; \mathrm{P}<0.001 ; \mathrm{N}=18$ sites $)$,

TABLE 1. Mean \pm SE (arithmetic means and standard errors of back-transformed data), test-statistic, degrees of freedom and p-values for the life history traits of the European Map butterfly (Araschnia levana). The dependence on altitude and temperature is shown (significant P-values are presented in bold). Sex was used as an additional fixed factor for larval and pupal weight, larval development time, pupal and adult life span. Percentage mortality at each site was related to temperature and altitude.

\begin{tabular}{|c|c|c|c|c|}
\hline & Mean \pm SE & Test-statistic & $\mathrm{N}$ & $\mathrm{P}$ \\
\hline $\begin{array}{l}\text { Larval weight (mg) } \\
\text { (mg }\end{array}$ & $72.03 \pm 3.48$ & & 156 & \\
\hline Females & $78.63 \pm 5.54$ & & 76 & \\
\hline Males & $65.76 \pm 4.19$ & & 80 & \\
\hline \multicolumn{5}{|l|}{ Altitude } \\
\hline Sex & & $\mathrm{F}_{1,140}=4.20$ & 156 & 0.042 \\
\hline Altitude & & $\mathrm{F}_{1,13}=9.83$ & 15 & 0.008 \\
\hline \multicolumn{5}{|l|}{ Temperature } \\
\hline Sex & & $\mathrm{F}_{1,140}=4.35$ & 156 & 0.039 \\
\hline Temperature & & $\mathrm{F}_{1,13}=18.96$ & 15 & $<0.001$ \\
\hline Pupal weight (mg) & $129.41 \pm 1.31$ & & 156 & \\
\hline Females & $140.01 \pm 1.59$ & & 76 & \\
\hline Males & $119.34 \pm 1.28$ & & 80 & \\
\hline \multicolumn{5}{|l|}{ Altitude } \\
\hline Sex & & $\mathrm{F}_{1,140}=104.35$ & 156 & $<0.001$ \\
\hline Altitude & & $\mathrm{F}_{1,13}=3.39$ & 15 & 0.089 \\
\hline \multicolumn{5}{|l|}{ Temperature } \\
\hline Sex & & $F_{1,140}=106.66$ & 156 & $<0.001$ \\
\hline Temperature & & $\mathrm{F}_{1,13}=6.69$ & 15 & $\mathbf{0 . 0 2 3}$ \\
\hline Larval development time (days) & $7.93 \pm 0.19$ & & 155 & \\
\hline Females & $8.14 \pm 0.26$ & & 76 & \\
\hline Males & $7.72 \pm 0.26$ & & 79 & \\
\hline \multicolumn{5}{|l|}{ Altitude } \\
\hline Sex & & $F_{1,139}=6.88$ & 155 & 0.010 \\
\hline Altitude & & $\mathrm{F}_{1,13}=10.58$ & 15 & 0.006 \\
\hline \multicolumn{5}{|l|}{ Temperature } \\
\hline Sex & & $\mathrm{F}_{1,139}=6.71$ & 155 & 0.011 \\
\hline Temperature & & $\mathrm{F}_{1,13}=19.27$ & 15 & $<0.001$ \\
\hline Pupal life span (days) & $11.26 \pm 0.07$ & & 155 & \\
\hline Females & $11.51 \pm 0.09$ & & 76 & \\
\hline Males & $11.01 \pm 0.09$ & & 79 & \\
\hline \multicolumn{5}{|l|}{ Altitude } \\
\hline Sex & & $F_{1,139}=13.93$ & 155 & $<0.001$ \\
\hline Altitude & & $\mathrm{F}_{1,13}=0.15$ & 15 & 0.709 \\
\hline \multicolumn{5}{|l|}{ Temperature } \\
\hline Sex & & $F_{1,139}=13.95$ & 155 & $<0.001$ \\
\hline Temperature & & $\mathrm{F}_{1,13}=0.37$ & 15 & 0.556 \\
\hline Adult life span (days) & $23.52 \pm 0.97$ & & 156 & \\
\hline Females & $27.32 \pm 1.56$ & & 76 & \\
\hline Males & $19.91 \pm 1.03$ & & 80 & \\
\hline \multicolumn{5}{|l|}{ Altitude } \\
\hline Sex & & $\mathrm{F}_{1,140}=16.10$ & 156 & $<0.001$ \\
\hline Altitude & & $\mathrm{F}_{1,13}<0.01$ & 15 & 0.990 \\
\hline \multicolumn{5}{|l|}{ Temperature } \\
\hline Sex & & $\mathrm{F}_{1,140}=16.10$ & 156 & $<0.001$ \\
\hline Temperature & & $\mathrm{F}_{1,13}=0.20$ & 15 & 0.661 \\
\hline \multicolumn{5}{|l|}{ Mortality in the field } \\
\hline Altitude & & $\mathrm{F}_{1,16}=2.91$ & 18 & 0.107 \\
\hline Temperature & & $F_{1,16}=4.15$ & 18 & 0.059 \\
\hline \multicolumn{5}{|l|}{ Mortality in the laboratory } \\
\hline Altitude & & $\mathrm{F}_{1,13}=0.13$ & 15 & 0.724 \\
\hline Temperature & & $\mathrm{F}_{1,13}=0.10$ & 15 & 0.757 \\
\hline
\end{tabular}



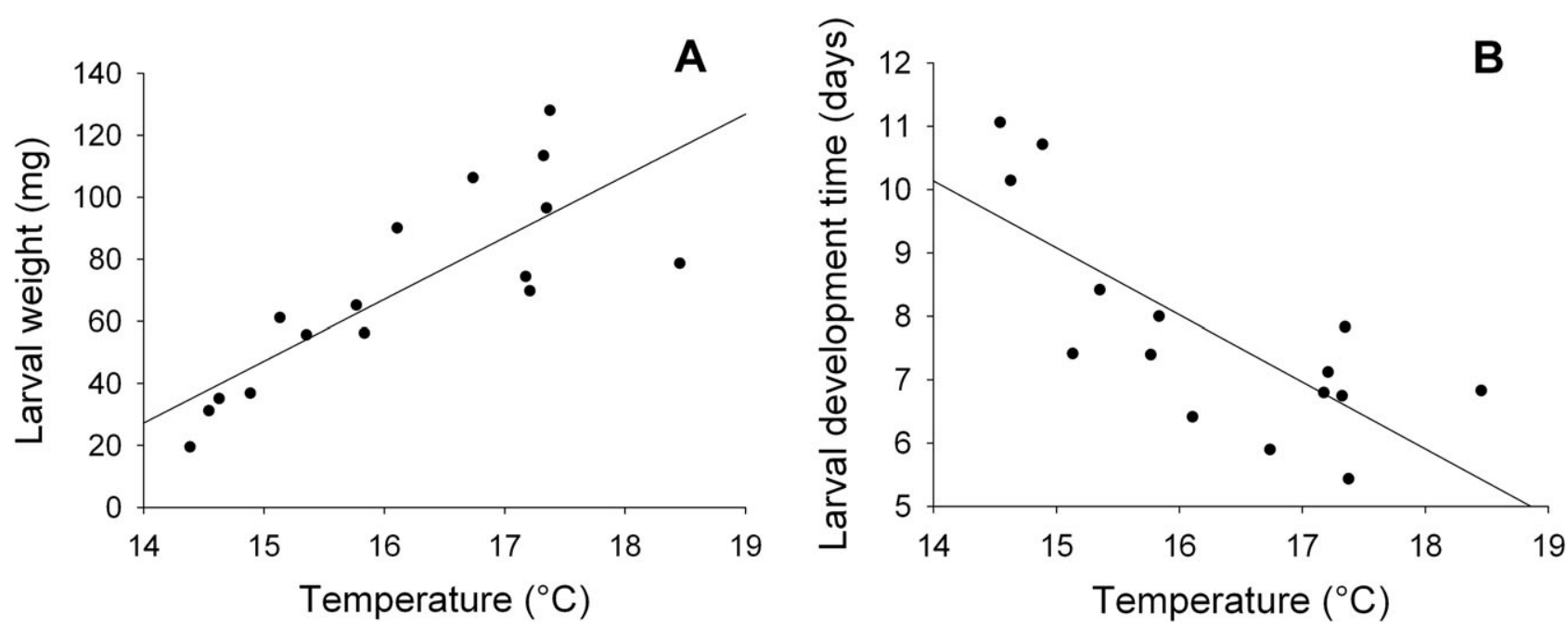

Fig. 1. Relationship between life history traits of the European Map butterfly (Araschnia levana) and temperature: A - mean larval weight for each site $\left(\mathrm{y}=19.91 \mathrm{x}-251.54 ; \mathrm{R}^{2}=0.642 ; \mathrm{P}<0.001 ; \mathrm{N}=16\right.$ sites); $\mathrm{B}$ - mean larval development time (from collecting to pupation) for each site $\left(\mathrm{y}=-1.06 \mathrm{x}+24.93 ; \mathrm{R}^{2}=0.570 ; \mathrm{P}=0.001 ; \mathrm{N}=15\right.$ sites $)$.

which confirms that both altitude and temperature can be used as alternative explanatory variables.

\section{Mortality and percentage parasitism}

Of the 540 larvae placed at the 18 sites along an altitudinal gradient a total of 188 larvae were found and collected from 16 sites after 3 weeks. At two of the sites no larvae were found. Thus, the average percentage mortality of larvae per site is $65 \%$. Percentage larval mortality did not change significantly with temperature or altitude, even though there was a tendency for the percentage mortality to increase in the field with increase in temperature (Table 1). No parasitoids emerged from the butterfly larvae.

\section{Life history traits}

There was a strong relationship between altitude/temperature and the weight of the butterfly larvae (Table 1; Fig. 1A) and between altitude/temperature and length of larval development (Table 1; Fig. 1B), whereas other life history parameters were not associated with altitude or temperature (all $\mathrm{P}>0.1$; Table 1 ). All the traits of the female and male larvae differed significantly. Female larvae and pupae were heavier than those of males (Table 1). Females lived longer than males and took longer to develop and spent longer in the pupal stage (Table 1). None of the interactions between sex $x$ altitude or sex $x$ temperature had a significant effect on the life-histories (all $\mathrm{P}>0.05$ ).

\section{DISCUSSION}

As cited in the literature there was a decrease of $0.6^{\circ} \mathrm{C}$ for every $100 \mathrm{~m}$ increase in altitude (e.g. Rolland, 2003). As predicted, the life history traits of the European Map butterfly (Araschnia levana) changed with increase in altitude and decrease in temperature. Life histories of females and males differed, but did not interact with altitude or temperature. Comparison of the associations between life history traits with altitude and temperature, revealed that the association with temperature was higher than with altitude, which indicates the usefulness of measuring temperature in addition to altitude at each location.

\section{Mortality and percentage parasitism}

Species are restricted to defined climatic envelopes (Walther et al., 2002). If climate becomes less favourable, deviations from the optimal temperature can result in increased mortality (Alonso 1999; Karban \& Strauss, 2004). Therefore, an increase in mortality with increase in altitude was expected. However, there were no significant negative associations between percentage mortality and increase in altitude and decrease in temperature. This might be because the larvae collected from the field were all reared under the same temperature conditions.

As the species richness of insects generally decreases with increase in altitude and increase in harshness of the climatic conditions at high altitudes (Begon et al., 1996) it was assumed that percentage parasitism would be lower at the higher altitudes. However, none of the larvae collected were parasitized, even those collected at low altitudes. In theory, less favourable conditions and longer development times of the host lead to increased percentage parasitism (Benrey \& Denno, 1997), but at this study site only bottom-up effects controlled the system and top-down-control by parasitoids did not occur. Larval development is more strongly determined by host plant quality and abiotic environmental factors (bottom-up control) than by top down control (Hunter et al., 1997). The fact that the $A$. levana larvae were not parasitized might not be due to the absence of parasitoids, but due to the parasitoids being unable to detect the larvae in the newly planted experimental nettle plots. Microclimatic conditions, a too low population density of A. levana or possible chemical and landscape properties may have contributed to the lack of parasitoids. Nevertheless none of the 208 larvae of $A$. levana collected in an extensive survey of sites where nettles were growing naturally, in 
the same area as the study sites, (Fichtelgebirge) in 2009 were parasitized (Wagner, unpubl. data). Also the author of an unpublished thesis from Sweden reports not finding any parasitized $A$. levana larvae, which is attributed to the relatively recent colonization of Sweden by $A$. levana (Söderlind, 2009, unpubl).

\section{Life history traits}

As the rate of development in insects strongly depends on temperature (Van Doorslaer \& Stoks, 2005; Bernardo et al., 2006) it is assumed that they adapt to and have different developmental strategies at different altitudes (Karl et al., 2008). Laboratory studies provide evidence that an interaction between temperature and the origin of butterflies affect larval growth rates and adult fecundity (Burke et al., 2005; Karlsson \& Van Dyck, 2005; Nylin, 2009). In accordance with other altitudinal studies, the larvae of A. levana were lighter and took longer to develop at high compared to low altitudes, presumably because of the lower temperatures and high plasticity (e.g. Alonso, 1999).

The comparison of insects collected from low and high altitudes has revealed that developmental rate increases with altitude (Berner et al., 2004). This increase in developmental rate is associated with an increase in metabolic rate (Terblanche et al., 2009). In the current study the individuals originally came from sites at a low altitude. Their response to high altitudes might be an adaptive response to local climate facilitated by high phenotypic plasticity (Berner et al., 2004). In another transplant experiment craneflies that were transferred from a high altitude to a lower altitude emerged at the same time despite the differences in temperature (Coulson et al., 1976). This result contrasts with those of the current study in which larvae from lower sites developed more slowly and were less fit due to the lower temperatures at the higher altitudes, probably not for genetic reasons but because of their high plasticity.

Furthermore females took longer to complete their larval and pupal development than males. This accords with other laboratory studies and might be caused by protandry (Bauerfeind et al., 2009), which may also account for the lower weight of male butterfly larvae and pupae (Fischer \& Fiedler, 2001).

\section{CONCLUSION}

The results indicate that altitudinal and temperature gradients affect the life history traits of the European Map butterfly (Araschnia levana). The assumption that butterflies at higher altitudes develop more slowly and fewer survive because of unsuitable climatic conditions could only partly be confirmed. The lower weights and slower development recorded at high altitudes compared to low altitudes, where the temperatures were higher, is probably a consequence of this species phenotypic plasticity. Sex differences in larval weight, pupal and adult lifespan might be due to protandry. The absence of parasitoids prevented a comparison of percentage parasitism at different altitudes and a test of the hypothesis that increasing temperatures might disrupt biotic interactions e. g. in the synchrony between parasitoids and hosts. However, the complete absence of natural antagonists either indicates that this kind of disruption has occurred or that top-down regulation of $A$. levana populations plays a minor role.

ACKNOWLEDGEMENTS. We thank M. Konvicka, two anonymous referees, S. Brückmann, I. Karl and J. Steckel for helpful suggestions on how the manuscript could be improved, A. Aures, M. Ewald, A. Guhr, J. Hager, T. Leipold, N. Lüdtke and N.-N. Moske for help with collecting and feeding Araschnia levana. This project was supported by the Deutsche Forschungsgemeinschaft (Effects of climate change on altitudinal distribution, trophic interactions and genetic diversity of butterflies in low-mountain regions; Contract Number STE 957/8-1 to ISD and JK).

\section{REFERENCES}

Alonso C. 1999: Variation in herbivory by Yponomeuta Mahalebella on its only host plant Prunus mahaleb along an elevational gradient. Ecol. Entomol. 24: 371-379.

Angilletta M.J. \& Dunham A.E. 2003: The temperature-size rule in ectotherms: simple evolutionary explanations may not be general. Am. Nat. 162: 332-342.

Bale J.S., Masters G.J., Hodkinson I.D., Awmack C., Bezemer T.M., Brown V.K., Butterfield J., Buse A., Coulson J.C., Farrar J., Good J.E.G., Harrington R., Hartley S., Jones T.H., Lindroth R.L., Press M.C., Symrnioudis I., Watt A.D. \& WhitTAKer J.B. 2002: Herbivory in global climate change research: direct effects of rising temperature on insect herbivores. Glob. Change Biol. 8: 1-16.

Bauerfeind S.S., Perlick J.E.C. \& Fischer K. 2009: Disentangling environmental effects on adult life span in a butterfly across the metamorphic boundary. Exp. Geront. 44: 805-811.

Begon M.E., Harper J.L. \& Townsend C.R. 1996: Ecology. 3rd ed. Blackwell, Oxford, 1068 pp.

BenRey B. \& Denno R.F. 1997: The slow-growth-high-mortality hypothesis: A test using the cabbage butterfly. Ecology $\mathbf{7 8}$ : 987-999.

Bernardo U., Pedata P.A. \& Viggiani G. 2006: Life history of Pnigalio soemius (Walker) (Hymenoptera: Eulophidae) and its impact on a leafminer host through parasitization, destructive host-feeding and host-stinging behaviour. Biol. Control 37: $98-107$.

Berner D., KöRner C. \& BlanCKenhorn W.U. 2004: Grasshopper populations across $2000 \mathrm{~m}$ of altitude: is there life history adaptation? Ecography 27: 733-740.

Both C., van Asch M., BiJlsma R.G., van den Burg A.B. \& VISSER M.E. 2009: Climate change and unequal phenological changes across four trophic levels: constraints or adaptations? J. Anim. Ecol. 78: 73-83.

Bourn N.A.D. \& Thomas J.A. 2002: The challenge of conserving grassland insects at the margins of their range in Europe. Biol. Conserv. 104: 285-292.

Brückmann S.V., Krauss J., van Achterberg C. \& SteffanDewenter I. 2011: The impact of habitat fragmentation on trophic interactions of the monophagous butterfly Polyommatus coridon. $J$. Insect Conserv. (in press: DOI: 10.1007/s10841-010-9370-7).

Burke S., Pullin A.S., Wilson R.J. \& Thomas C.D. 2005: Selection for discontinuous life-history traits along a continuous thermal gradient in the butterfly Aricia agestis. Ecol. Entomol. 30: 613-619.

Buse A., Hadley D. \& Sparks T. 2001: Arthropod distribution on an alpine elevational gradient: the relationship with pre- 
ferred temperature and cold tolerance. Eur. J. Entomol. 98: 301-309.

Coulson J.C., Horobin J.C., Butterfield J. \& Smith G.R.J. 1976: Maintenance of annual life-cycles in 2 species of Tipulidae (Diptera) - field study relating development, temperature and altitude. J. Anim. Ecol. 45: 215-233.

Ebert G. \& Rennwald E. 1991: Die Schmetterlinge BadenWürttembergs. Band 1, Tagfalter I., Band 2, Tagfalter II. Ulmer, Stuttgart, 552 pp., 535 pp.

Fischer K. \& FiedLer K. 2001: Dimorphic growth patterns and sex-specific reaction norms in the butterfly Lycaena hippothoe sumadiensis. J. Evol. Biol. 14: 210-218.

Franco A.M.A., Hill J.K., Kitschke C., Collingham Y.C., Roy D.B., Fox R., Huntley B. \& Thomas C.D. 2006: Impacts of climate warming and habitat loss on extinctions at species' low-latitude range boundaries. Glob. Change Biol. 12: $1545-1553$.

Fric Z. \& Konvicka M. 2002: Generations of the polyphenic butterfly Araschnia levana differ in body design. Evol. Ecol. Res. 4: 1017-1032.

Herting B. \& Simmonds F.J. 1976: A Catalogue of Parasites and Predators of Terrestrial Arthropods. Section A. Host or Prey/Enemy. Volume VII. Lepidoptera, Part 2 (Macrolepidoptera). Royal Commonwealth Agriculture Bureaux, Farnham, $221 \mathrm{pp}$.

HodKINSON I.D. 2005: Terrestrial insects along elevation gradients: species and community responses to altitude. Biol. Rev. 80: 489-513.

Holt R.D. \& Barfield M. 2009: Trophic interactions and range limits: the diverse roles of predation. Proc. R. Soc. (B) 276: 1435-1442.

Hunter M.D., Varley G.C. \& Gradwell G.R. 1997: Estimating the relative roles of top-down and bottom-up forces on insect herbivore populations: a classic study revisited. Proc. Natl. Acad. Sci. USA 94: 9176-9181.

Karban R. \& Strauss S.Y. 2004: Physiological tolerance, climate change, and a northward range shift in the spittlebug, Philaenus spumarius. Ecol. Entomol. 29: 251-254.

KARL I. \& Fischer K. 2008: Why get big in the cold? Towards a solution to a life-history puzzle. Oecologia 155: 215-225.

Karl I., Janowitz S.A. \& Fischer K. 2008: Altitudinal lifehistory variation and thermal adaptation in the copper butterfly Lycaena tityrus. Oikos 117: 778-788.

KARLSSON B. \& VAN DYCK H. 2005: Does habitat fragmentation affect temperature-related life-history traits? A laboratory test with a woodland butterfly. Proc. R. Soc. (B) 272: 1257-1263.

Konvicka M., Maradova M., Benes J., Fric Z. \& KepKa P. 2003: Uphill shifts in distribution of butterflies in the Czech Republic: effects of changing climate detected on a regional scale. Glob. Ecol. Biogeogr. 12: 403-410.

McCARTY J.P. 2001: Ecological consequences of recent climate change. Conserv. Biol. 15: 320-331.

Merrill R.M., Gutierrez D., Lewis O.T., Gutierrez J., Diez S.B. \& Wilson R.J. 2008: Combined effects of climate and biotic interactions on the elevational range of a phytophagous insect. J. Anim. Ecol. 77: 145-155.

NYLIN S. 2009: Gradients in butterfly biology. In Settele J., Shreeve T., Konvicka M. \& Van Dyck H. (eds): Ecology of Butterflies in Europe. Cambridge University Press, Cambridge, pp. 198-216.

PARMESAN C. 2001: Coping with modern times? Insect movement and climate change. In Reynolds D.R. \& Thomas C.D. (eds): Insect Movement, Mechanisms and Consequences: Proceedings of the Royal Entomological Society's 20th Symposium (Symposia of the Royal Entomological Society of London). CABI, Wallingford, pp. 387-414.

PARMesan C. 2006: Ecological and evolutionary responses to recent climate change. Annu. Rev. Evol. Syst. 37: 637-669.

Parmesan C. \& Yohe G. 2003: A globally coherent fingerprint of climate change impacts across natural systems. Nature 421: $37-42$.

Parmesan C., Ryrholm N., Stefanescu C., Hill J.K., Thomas C.D., Descimon H., Huntley B., Kaila L., Kullberg J., Tammaru T., Tennent W.J., Thomas J.A. \& Warren M. 1999: Poleward shifts in geographical ranges of butterfly species associated with regional warming. Nature 399: 579-583.

Pinheiro J., Bates D., Deb Roy S., Sarkar D. \& the R Development Core Team 2010:. nlme: Linear and Nonlinear Mixed Effects Models. R package version 3.1-97.

Primack R.B., Ibanez I., Higuchi H., Lee S.D., Miller-Rushing A.J., Wilson A.M. \& Silander J.A. 2009: Spatial and interspecific variability in phenological responses to warming temperatures. Biol. Conserv. 142: 2569-2577.

Rolland C. 2003: Spatial and seasonal variations of air temperature lapse rates in Alpine regions. J. Climate 16: $1032-1046$

Root T.L., Price J.T., Hall K.R., Schneider S.H., Rosenzweig C. \& Pounds J.A. 2003: Fingerprints of global warming on wild animals and plants. Nature 421: 57-60.

Schweiger O., Biesmeijer J.C., Bommarco R., Hickler T., Hulme P.E., Klotz1 S., Kühn I., Moora M., Nielsen A., Ohlemüller R., Petanidou T., Potts S.G., Pyšek P., Stout J.C., Sykes M.T., Tscheulin T., Vilà M., Walther G.-R., Westphal C., Winter M., Zobel M. \& Settele J. 2010: Multiple stressors on biotic interactions: how climate change and alien species interact to affect pollination. Biol. Rev. 85: 777-795.

SöDERLIND C. 2009: Parasitism in an Expanding Species - Has the European Map Butterfly Escaped from its Natural Enemies? Thesis, Institutionen för Ekologi, Sveriges Lantbruksuniversitet, Uppsala, 37 pp. [in Swedish, English abstr.].

Terblanche J.S., Clusella-Trullas S., Deere J.A., Van VuURen B.J. \& Chown S.L. 2009: Directional evolution of the slope of the metabolic rate-temperature relationship is correlated with climate. Physiol. Biochem. Zool. 82: 495-503.

Van Doorslaer W. \& Stoks R. 2005: Thermal reaction norms in two Coenagrion damselfly species: contrasting embryonic and larval life-history traits. Freshwat. Biol. 50: 1982-1990.

Walther G.R., Post E., Convey P., Menzel A., Parmesan C., Beebee T.J.C., Fromentin J.M., Hoegh-Guldberg O. \& BairLEIN F. 2002: Ecological responses to recent climate change. Nature 416: 389-395.

Warren M.S., Hill J.K., Thomas J.A., Asher J., Fox R., Huntley B., Roy D.B., Telfer M.G., Jeffcoate S., Harding P., Jeffcoate G., Willis S.G., Greatorex-Davies J.N., Moss D. \& Thomas C.D. 2001: Rapid responses of British butterflies to opposing forces of climate and habitat change. Nature 414: 65-69.

Wilson R.J., Gutierrez D., Gutierrez J. \& Monserrat V.J. 2007: An elevational shift in butterfly species richness and composition accompanying recent climate change. Glob. Change Biol. 13: 1873-1887.

Received November 18, 2010; revised and accepted February 1, 2011 